\title{
THE CONTEMPORARY STRATEGIC CHALLENGES FACING HIGHER EDUCATION
}

\author{
Venelin Terziev ${ }^{1}$, Marusya Lyubcheva ${ }^{2}$, Marin Georgiev ${ }^{3}$ \\ ${ }^{1}$ Full Member of the Russian Academy of Natural History, Professor, Eng., D.Sc. (National \\ Security), D.Sc. (Economics), D.Sc. (Social Activities), Ph.D. \\ Russian Academy of Natural History, Moscow, Russia \\ Georgi Rakovski Military Academy, Sofia, Bulgaria \\ University of Rousse, Rousse, Bulgaria \\ Kaneff University Hospital, Rousse, Bulgaria \\ vkterziev@gmail.com \\ ${ }^{2}$ Associate Professor, Ph.D., University “Prof. d-r Assen Zlatarov”, Bourgas, Bulgaria \\ milyubcheff@gmail.com \\ ${ }^{3}$ Ph.D., Kaneff University Hospital, Ruse, Bulgaria, clementon@abv.bg
}

\begin{abstract}
The article addresses the challenges facing higher education, related to the demographic problems and the quality of process management. The free movement and the single education area are changing attitudes, especially those of young people and their choice where to receive education. The demographic crisis, migration and the lower quality of previous levels of education are further exacerbating the situation in higher education. The article argues that a change in the educational management is necessary in order to find solutions to deficits and to build a model of 'engaged universities' where the quality of education is maintained at a level consistent with socio-economic processes.
\end{abstract}

Keywords: higher education, contemporary, changes, management.

\section{INTRODUCTION}

Recently, a lot has been said and written about the development of Bulgarian higher education. We often try to find our place in lists of European and world rankings and are glad that accidentally or not quite accidentally we are in certain lists for the first time. We think of being somewhere in the list of 'contenders' as some kind of an achievement and an important assessment. Unfortunately, the process of restructuring the education system not only did not come to an end, but also in the process of transformation we turned out to be unprepared enough to even adapt to these dynamic periods of political transformation. Market mechanisms threw educational process into such confusion that it hardly reacts to the impact of the external environment.

In the years of the so-called 'transition to a market economy' the academic autonomy of higher education led to quite critical deviations from the normal functioning of the educational process, such as not respecting the mandate of the head, collective governing bodies are not elected in a very democratic way, increase in the number of professional areas in which training process is conducted without proven capacity, lack of any planning for these processes and a number of other deviations (Terziev \& Bogdanova, 2019).

It seems unlikely that these ongoing processes are not noticed by the numerous analysts and researchers, 
by those who have to and who are responsible for 'preparing' strategic documents. However, the change turns out to be so difficult or almost impossible that for the last more than thirty years it has not practically happened.

The market mechanisms created certain conditions for establishing an infinite number and variety of institutes conducting training and producing this product called science, thus leading to disparities difficult to overcome.

\section{CHALLENGES FACING HIGHER EDUCATION}

In Bulgaria, the number of higher education institutions is more than 50 , and in recent years the number of vacant study places has always remained unfilled. Some of the reasons for this are due to the ongoing demographic processes and deepening the problem of population decline in the country. However, this is far from the main problem of the functioning of our education system. It is almost impossible to use old educational technologies and even successful policies from the past because they were at least in line with current realities then and sought to solve current problems. The existing ones do not give an answer to many questions. At the same time, competitors around us combine both past and future and are in the top lists of the rankings.

Opponents of all types of assessment might say that criteria are not the best, the conditions are different and the funding is not very good and sufficient enough. However, even if we assume that their thesis is defensible, we are in a certain situation and conditions under which we have to make the right and the best decisions.

If we look at the UniRank ranking results, published in recent months, we will see that it is based on several main criteria: to be licensed and/or accredited by the relevant higher education organization in each country, to offer at least four-year bachelor's and master's or PhD programmes, and to run own training courses mainly in conventional format. No Bulgarian university is included in the Top 200 of this ranking. However, what is more interesting is how they are distributed in Europe and which countries find their place in it. The leading positions are for the British education system - nearly $24 \%$ of universities are positioned there, followed by Germany with nearly $16 \%$. Spain and France rank after them. Practically, the group of elite universities is determined by these four countries. The respective definite positions are also held by representatives of the Netherlands with 10 universities, Italy - 9 universities, Switzerland and Russia with 7 universities each, etc. The Balkan countries are represented only by Greece.

Dozens of other rankings and evaluation systems of universities exist in the public space. In the best cases, several Bulgarian universities are in the forefront - Sofia University "St. Kliment Ohridski", the Technical and Medical Universities in Sofia.

The modernization of higher education is related to solving a complex of problems, which can be summarized in two groups: problems of superfluity and problems of insufficiency.

Obviously, there is a sufficient, and perhaps a great number of educational institutions, which in terms of the scientific infrastructure are unevenly distributed in the country. Most of them are concentrated in the capital and several of the country's larger cities. Most of them offer an educational product in almost all professional fields with a few exceptions. In this direction of thought, we cannot have a shortage of qualified staff and we should have enough expertise in almost all fields. Despite the state standards and requirements for accreditation procedures, not in all of them the offered (even the paid) service is of sufficiently good quality. At least two active parties take part in this process - those who offer it and those who receive it. It will not be difficult to find a set of criticisms of both, but justifiably the result does not meet our European standards and our expectations with a large part of these two groups in particular. Practically and theoretically, a problem with the effectiveness of this process exist, which of course is ongoing and quite complex in nature, something that makes it difficult to manage. Here is just a passing example that hardly answers all the questions that arise. In the last few years there has been a restrictive attitude towards a number of majors in the field of 'Economics' and 'Administration and Management', which comes to show us that in recent years a sufficient number of such personnel and expertise have been 'produced'. At the same time, almost every sociological study or survey in this direction reports a shortage of sufficiently well-trained managers, and even specialists in the field of finance and accounting. The answers and criticisms can be formulated in many directions, including the following: almost all universities provide training in these fields and the three Bulgarian universities of economics are placed in a particularly competitive environment, training in some of them is placed in a position of direct economic benefit to admit a certain number of students, one of the universities is located regionally in an area with a relatively small population size and not very good road infrastructure and communication links, which makes it isolated or in worse positions than the others. 
Essentially, all these statements are true. However, they do not answer the question why with such a surplus there is a shortage in the real primary market (Lyubcheva, Terziev, 2019a).

In other cases, some of the engineering fields remain supposedly promising and necessary although still unfilled and the students in these majors have a relatively low entry level.

Until we solve the set of problems in both directions and clarify the reasons for this, there is no way to implement and even think about a successful strategy in the field of higher education. It cannot develop alone and there is no way to adapt to the situation in a 'market' way, because planning is the main component of the management process. Planning good actions in this direction is an emanation of advanced flying in management and cannot be an action taken by one individual, or even by an entire ministry. Therefore, before moving from one programming period to another in education funding (according to the established practice of the European Union), we must seek to solve these crisis problems, which are not a consequence of a pandemic situation or other crisis phenomena, but of the lack of professional analysis, proper programming and good policy.

When we look for the solution of economic, political or other problems that occur every day and will not go away in the future, we must thoroughly analyze the educational and cultural processes, their nature and specific manifestation in our country.

\section{THE CURRENT AGENDA FOR HIGHER EDUCATION}

Currently, higher education is associated with new topics impossible to be discussed a decade ago, a decade relating to a new reality in social development that has emerged in the last few years. The discussion space is occupied by Industry $4.0,5 \mathrm{G}$ even $6 \mathrm{G}$ network, we use terminology that until yesterday could be seen only in the dreams of some innovative researchers. Universities are part of the top competence centers, part of the strategic guidelines for smart development. If so far we have been looking for options on how education can respond to the rapidly evolving high technologies, today we are already looking for opportunities to integrate education into the cloud technologies and the creation of artificial intelligence and supercomputers. At first glance, this is a challenge, but viewed from the standpoint of the process of consistency and upgrading knowledge, skills and competencies in recent years, it can be defined as a systematic logical and consistent development. The preconditions for similar development were created in a theoretical aspect. However, achievements were reported only in individual universities ranking first in the rating schemes. Achievements and challenges have different dimensions - some are 'high', others quite trivial, yet still significant (See Fig. 1).

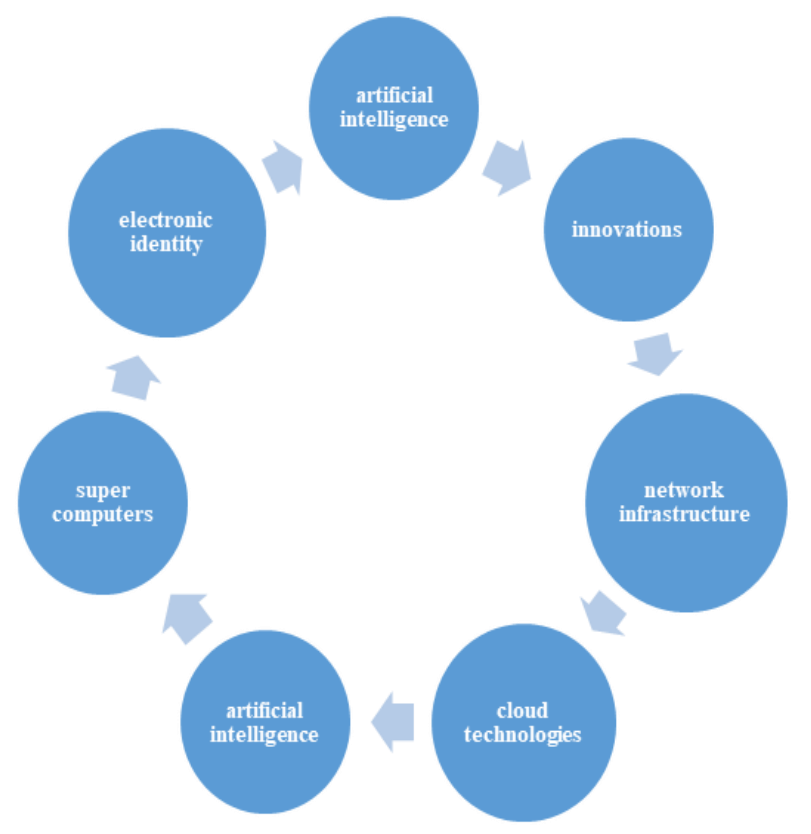

Figure 1: Challenges facing higher education

Higher education with its system has always developed in different fields of science and has made changes aiming to train professionals for the relevant economic sectors. With different structures which are subject to foundations providing sustainability and conditions for innovations that update it to be beneficial to society. 
Education has always been required a lot - to provide specialists for various positions in industry and all economic fields, to be a good basis for research, to provide conditions for personal development, mainly to young people, although not posing age restrictions, especially in the last years of people's working life. To a greater or lesser extent, the correspondence between supply and needs is ensured both by the quality of the process itself and by the quantity of the educational service offered.

We are facing a number of challenges related to the exceptional dynamics in the development of high technologies and information and communication systems, to the risks of quality management and human resources, and to the problems posed by the demographic crisis. In similar multi-directionality, higher education proved to be insufficiently prepared to be able to effectively counteract the accompanying risks (see Fig. 2).

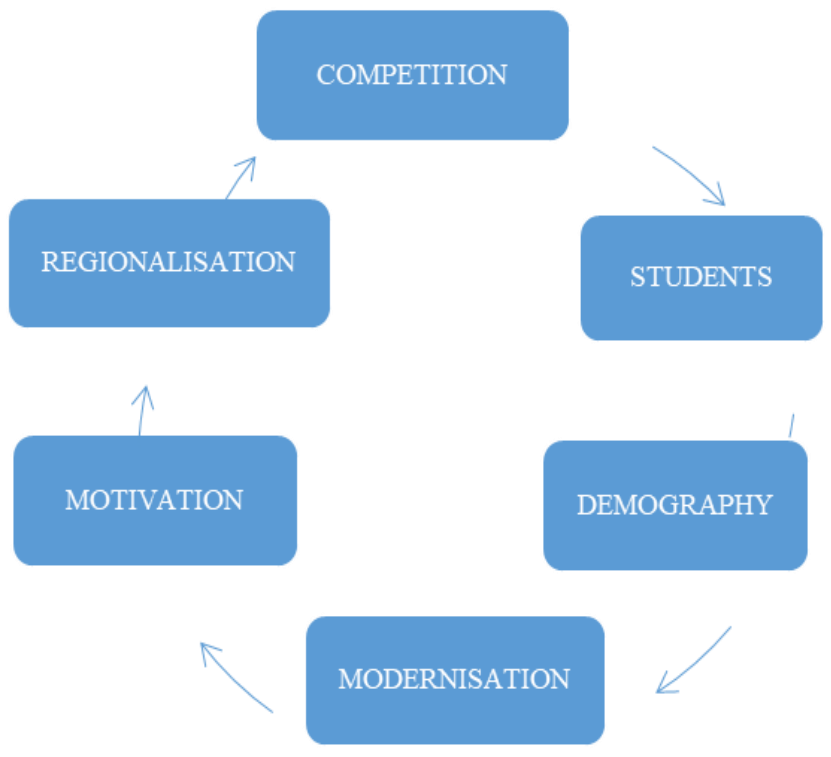

Figure 2: Environmental factors, generating risks to higher education in Bulgaria

The reasons for similar unpreparedness are related to managing the resources available to higher education - human, financial and material. These three key factors also include the possibilities for overcoming or deepening the problems. An analysis of the risks of resource management in the higher education system can suggest the strengths and weaknesses of this management. Such an analysis is often considered unnecessary, with the argument that everything is regulated in the legal framework of higher education and the presumption that everything is determined by the law. However, beyond the law things look different enough. Higher education depends on a lot of factors and circumstances - political, economic, financial, structural, organizational, etc. Some of them are external to the system, others are part of it; together they cause serious discomfort. Consistent discussion and analysis can change the picture, yet it is important to view them in the context of the overall social and economic situation, because 'isolated' analyses lead to partial and sometimes erroneous decisions. As far as external factors are concerned, serious attention should be paid to demographic problems. Several key points can be outlined in this respect - decline in the birth rate and a decrease in the number of children, and of high school leavers, respectively; multidirectional and high-intensity migration processes from Bulgaria to foreign countries (universities); low quality of secondary education and an increase in the number of bilinguals in the education system, which inevitably affects higher education. These factors change the nature of the existing inflow into the higher education system, impacts on its quality and directly affects the realization of young graduates. This, in turn, requires a serious comprehensive analysis of the problems in all educational levels - based on well-organized statistical information and situational relationships (Terziev, Lyubcheva, 2020).

\section{HIGHER EDUCATION AND THE CHALLENGE OF DEMOGRAPHIC PROBLEMS}

The demographic problem is not only a problem of the Ministry of Labour and Social Policy and of the experts who develop strategies and measures to overcome the negative trends. Measures taken to reduce the state quota for public universities, especially in some professional fields, do not solve the problems associated with the declining number of student applicants either. In the last few years, the same thing has been repeatedly observed - the number of school leavers is close to the total capacity of all universities, a large percentage of unfilled state quota study places in universities, changes in the rules for admission 
during the campaign to 'fill' all study places, etc. During the 2019 - 2020 academic year applicant student campaign we witnessed various innovative tools used to motivate young people to enroll in higher education institutions (awards for students, bonuses for lecturers, etc.). In itself, this is already a clear indicator of the deepening crisis in the system due to fewer and fewer number of pupils, determined by the low birth rate, which is part of the big demographic problem. Here are the figures for the 2020/2021 academic year:

- Secondary education school leavers in 2019/2020 in comprehensive and vocational high schools were 25,800 and 21,600 students, respectively /a total of $47,400 /$;

- For the 2020/21 academic year, the state quota for higher education institutions is 54,334, of which 43,960 after secondary education. Admissions to private universities are not included here, which further exacerbates the situation.

The difference between high school leavers and potential first-year students is 3,440 . Of course, the key to the problems should not be made absolute and sought in the calculation of specific statistics. However, they actually point to a problem that has existed for years and is the basis for a number of subsequent ones. For some majors, the state quota for universities is reduced to 5,6 or 7 , which implies individual or some kind of training attached to another major. This also applies to some technical sciences, despite the emerging deficits in the technical and technological industries.

The small number of school leavers, even if we include prospective students from former alumni, allows us to keep applying lower admission criteria in order to be able to fill the approved quota. It is clear that a similar approach results in deteriorating the quality of training and reducing it to the level of perception of the enrolled applicants.

\section{HIGHER EDUCATION AND MIGRATION}

The flow of young people to foreign universities, especially after the mid-1990s, is quite serious. In some years, $100 \%$ of the students leaving the so called language schools, become students at foreign universities. Without imposing restrictions on the freedom of choice of the students and their families, it is necessary to look for appropriate models through which this flow can be reduced. Migration comprises several elements the state loses its good human resources, given that students that go to study abroad are with a very good level of preparation; most of the students who graduate abroad do not return to Bulgaria at all - i.e. Bulgaria is declining in population; these pupils and students are already working for other economies and, no matter how much we believe that we are in a single European education and single European economic area, this is an economic and in particular a financial loss for our country. For this purpose we have to conduct our own analysis and compare the level of Bulgarian universities with the foreign ones, i.e. to do an analysis to answer the question why this is happening and whether there is an objective situation for it to continue to happen. Obviously, not only a good command of foreign languages is a factor that determines this process. There are students who study the language of the respective country in the first year of their studies (a requirement of universities). Therefore it is important to conduct an analysis of higher education in our country with regard to organization, quality, and opportunities for realization after graduation and compare it with higher education in other countries. The issue of realization is related to the correspondence between higher education and the economy. Even with a very high quality of education, many young specialists will not be able to realize professionally if a lack of conformity exists. This will inevitably reflect the interest of future generations in university education or at least in some of the universities and certain majors. This problem is part of the 'brain drain' problem. It is not a Bulgarian patent, although our country has suffered from it more than other European countries, as it is combined with the deteriorating demographic situation.

\section{HIGHER EDUCATION AND THE QUALITY OF SECONDARY EDUCATION}

Another significant risk for the higher education system arises from the increased number of bilinguals, i.e. children and students for whom Bulgarian is not their mother tongue. The problems related to this element of the risk are mainly concentrated in secondary education. However, the increase in the percentage of high school leavers in this group ultimately affects the next level of education. It is a well-known fact that secondary education is not particularly successful, as evidenced by a number of studies. In the process of education and the transition from lower to higher level, higher education must take into account the level of knowledge acquired in previous levels. If it does not, it will not admit the necessary number of students. The dilemma in this case is quite serious. Combined with migration data, this is a very serious challenge for the academic community. It determines the decreasing admission score for certain majors, as well as the shortage of applicant students to fill the university quotas.

All three elements of risk discussed so far are related to human resource management - both inside and 
outside universities. The question of today's transformations of social relations is whether and how universities can incorporate into them and influence policies, including those for demographic process management (Terziev, 2020a).

\section{HIGHER EDUCATION AND ITS BENEFITS TO THE COUNTRY POLICIES}

The modernization of higher education is subject to an assessment of the capacity of its teaching and research potential and its participation in the social development of the country. Although no unified study exists on this topic, apart from the existing Act on the Development of Academic Staff and the registers certifying the actual state of this potential, its importance is emphasized at all levels. In the context of the above discussed demographic problems affecting higher education, it is important to take into account the participation of academic potential in solving problems of higher education, i.e. the possibility that the country's academic potential is actively involved in the formation and implementation of policies and strategies that will improve the situation (Terziev, 2020a).

In addition to the definition of academic staff, which is usually recognized by the main activities (teaching and research), another one can also be added - its inclusion in the economic and social processes. This defines the role of this group as extremely important for the economy and social life. The higher education sector is key to the transition to a knowledge society and preparing human resources to achieve it. In this context, it is obvious that universities have sufficient resources and capacity to be at the center of strategic solutions to the demographic problem and to offer workable and appropriate solutions. On the one hand, because they have a good grasp of the research methodologies have sufficient databases, are able to form complex teams, and have contacts at international level to apply good practices. On the other hand, universities are in contact with the younger generations and are familiar with their mentality and mood, which allows them to model solutions while working with them, to orient the development of young people in a direction promoting participation in social processes that are not focused on personal careers only. In addition, what interests universities is these young generations to work for the development of the country, to choose Bulgarian universities, and to enrich the banks with staff representing Bulgarian science and industry. Representatives of the academic community are not always sought after and welcomed to take part in the formation of policies, strategies, programmes and projects. However, this is practically the right way, especially since many universities offer majors close to the issues related to demographics. In a number of universities, it is appropriate to introduce majors or training programmes related to demographics. This can happen on the basis of strong differentiation and horizontal expansion of specializations in higher education, and be consistent with the fact that higher education depends on the external social conditions in which it operates, including the demographic ones.

Back in 2012, the European Parliament issued an appeal for 'engaged higher education institutions' and in its resolution on the modernization of higher education systems in Europe encouraged them: "higher education institutions to engage more intensively with their regions and establish dynamic collaborative actions with regional governments, local councils, public bodies, non-governmental organizations and small and medium-sized enterprises to enhance regional development" (European Parliament, 2012).

The involvement of the academic staff in the work of a number of state institutions, which is of course a bilateral process, can be increased, for example, by establishing permanent scientific advisory bodies (councils) to judge on all issues related to the demographic development of Bulgaria and the respective specific policies. Scientists and academic professors - sociologists, economists, educationalists, etc. are the most appropriate members of these bodies. The problem is multifaceted and needs comprehensive studies, analyses and development of strategies in many areas. The role of the state when determining and involving the academic community in the process of solving the political, economic and social priorities of the society must be taken into account.

\section{CONCLUSION}

The academic community owes a lot to younger generations in terms of their preferences to study abroad instead of studying in the country, because their decision is often made on the basis of not being informed enough about the state of higher education in Bulgaria - what majors are available and the level of training they offer. Presumably, the decision "I want to study abroad" is ineffective and sometimes wrong. Probably it explains the reason why many young people, who went to study abroad immediately after leaving high school, study for a very long time, most of them do not graduate, some return to our country, and only a few continue with their education. The applicant student campaigns alone are insufficient for school leavers to be informed well enough about the potential of higher education in our country (Terziev, Bogdanova, 2019). 
The applicant student reference guide books are not very useful either. The information they contain is provided in such a complicated way that sometimes you think you need a higher education degree to be able to understand it. The real link between universities and secondary schools is mandatory, and it must be a long-term and permanent relationship. Young generations are raised and brought up with difficulty throughout the period of adolescence. In addition to the direct link between higher and secondary education, the higher commitment of universities to the topic will create an appropriate public environment that can purposefully affect this process. Parents are part of this social environment. In most cases they are promoters of studying abroad without having enough information about the state of higher education in our country. Very often they are guided by the presumption that almost everything is bad in our country.

The role of the academic staff is to disseminate and share knowledge and information, to play the role of educator in the most general sense of the word. This will by no means lessen, on the contrary, it will increase the authority of lecturers and researchers. The effort of the academic community put into promoting and incorporating democratic values, into providing an environment for achieving inclusive and sustainable growth, which cannot happen without a strategic change in the attitude to demographic problems is significant. The work of universities is focused on providing physical and information-communication access to university structures, programmes and research, as well as on knowledge transfer.

Another focus in this direction is advertising. Why it is possible for the World Education platform to be advertised in all possible ways, while Bulgarian higher education is satisfied by a short exposition, information about which appears sporadically.

It is not good to promote higher education through awards given if enrolled in a university and this to be the only information that reaches public channels. The achievement of a university is the only advertisement that works. In good universities indoor advertising is at a high enough level.

We often tend to point out the problems, the negatives, and this creates conditions for a negative environment within the society, hostility and outflow of interest. Local communities do not know the academic community, while each university has excellent staff and good researchers who can present universities to the public. Knowledge is not just for 'behind the fence' of a university. Publicity is mandatory if we want to be liked and in order to be liked - they must know us. There are positive examples in this regard, when, for example, a municipality starts working with the universities on its territory, when the partnership becomes visible to the community, the interest in receiving education in these universities increases significantly. Nobody else but universities can change the situation with increasing the interest in Bulgarian universities. For example, municipal grants at a university on the territory of a particular municipality can do a wonderful job. In this respect, student councils would also be a good helper, they are not just groups for sports or election events. It is time to include criteria related to the benefits higher education provides to society when evaluating a university and the quality of higher education. Otherwise, the rating system will become a selfservice system that will not result in smart growth or knowledge economy, formulated by the Lisbon Strategy in 2000, but not yet achieved. More effort is required to achieve spiritual maturity and development, not just to survive, so that our progress can be accompanied not by decline but by the significance of successful development (Terziev, et al. 2020b; Ivanov, 2020c).

\section{REFERENCE LIST}

Terziev, V., Bogdanova, M. (2019). The academic capitalism and the new business model of the universities. Proceedings of ADVED 2019 - 5th International Conference on Advances in Education and Social Sciences (pp. 477-484). Istanbul, Turkey: International Organization Center of Academic Research.

Lyubcheva, M., Terziev, V. (2019a). The interaction: business- education - investment for development. XXII International Scientific Conference: The power of knowledge (pp. 1191-1196). Kavala, Greece: Institute of Knowledge Management, Skopje.

Terziev, V., Lyubcheva, M. (2020). Revolyutsiya v industrii i evolyutsiya v obrazovanii ili intelligentnoye razvitiye. Mezhdunarodnyy nauchnyy zhurnal «Internauka», Kiev, Ukraine, № 11 (91) / 2020, pp. 4855 (Терзиев, В., Любчева, М. Революция в индустрии и эволюция в образовании или интеллигентное развитие. // Международный научный журнал «Интернаука», Киев, Украина, № 11 (91) / 2020, с. 48-55, ISSN 2520-2057.

Terziev, V. (2020a). Science as a tool for social development. Review of Socio-Economic Perspectives, 
Ankara, Turkey, Vol 5(3), pp. 117- 134.

European Parliament. (2012). European Parliament resolution on modernizing Europe's higher education systems (2011/2294(INI)). European Parliament, 20 April 2012.

Terziev, V., Lyubcheva, M., Andreeva, O., Georgiev, M. (2020b). Revolution in industry and evolution in education or development of intelligence. //63rd International Scientific Conference on Economic and Social Development - "Building Resilient Society" - Zagreb, 11-12 December, 2020, Economic and Social Development (Book of Proceedings), Cakovec, Croatia, 2020, pp. 133-142, ISSN 1849-7535.

Ivanov, Ivan. (2020c). The labor market in the conditions of a pandemic crisis in Bulgaria. // Scientific Journal Society and Health, Regional Library "Lyuben Karavelov" Ruse, Kaneff University Hospital, Ruse, Bulgaria, 2020, Issue 2, book 1, pp. 40-55, ISSN 2683-0892. 